\title{
Influence of Flaw Inclination Angle on Cracking Behavior of Rock-Like Materials under Uniaxial Compression
}

\author{
Rongchao Xu $\mathbb{1}$ \\ College of Geosciences and Engineering, North China University of Water Resources and Electric Power, Zhengzhou, \\ Henan 450046, China \\ Correspondence should be addressed to Rongchao Xu; rcxirsm@126.com
}

Received 24 June 2019; Revised 22 July 2019; Accepted 18 August 2019; Published 23 October 2019

Guest Editor: Dariusz Rozumek

Copyright (c) 2019 Rongchao Xu. This is an open access article distributed under the Creative Commons Attribution License, which permits unrestricted use, distribution, and reproduction in any medium, provided the original work is properly cited.

The inclination angle of the flaw has an important effect on the cracking behavior of fractured rock. The influence of the inclination angle of closed flaw on the strength, cracking behavior, failure modes, and AE behaviors of specimens has not been investigated thoroughly. Uniaxial compression tests were conducted on gypsum samples containing a single closed flaw with different inclination angles. The flaw orientation influence on strength, cracking mechanism, failure modes, and AE behaviors was analyzed in detail. With the increase of the flaw inclination angle from $30^{\circ}$ to $75^{\circ}$, the mechanical parameters such as elastic modulus, wing crack initiation strength, and uniaxial compression strength decrease first and then increase and reach the minimum value at $45^{\circ}$. The wing crack initiation angle decreases from $65^{\circ}$ to $35^{\circ}$ as the flaw inclination angle increases from $30^{\circ}$ to $75^{\circ}$. The wing crack is more difficult to initiate from the tips of closed flaws compared with that of open flaws. The secondary cracks are initially shear cracks and propagate in a stable manner. However,when the axial stress reaches the peak strength, the secondary crack propagates unstably, which results in the macroscopic failure of the sample. The AE behaviors of samples are also analyzed during the uniaxial compression test. The experimental results are expected to provide helpful guidance for safe construction under fractured rock mass condition.

\section{Introduction}

Discontinuity of rock mass is a common phenomenon in slope engineering and underground engineering. A large number of engineering practices have proved that the instability and failure of rock mass engineering are closely related to the internal joints, flaws, and weak surfaces. In rock engineering, new cracks initiate from the tips of preexisting flaws and unstable failure of surrounding rocks will happen along with the coalescence of these cracks. In order to better understand the strength characteristics and cracking mechanisms of fractured rock, extensive research has been done under uniaxial compression [1-13].

The influence of the flaw inclination angle on cracking behavior has been extensively studied by many researchers. Bobet and Einstein [14] conducted compression tests on samples of gypsum to investigate the orientation influence on failure mechanism and crack coalescence modes. By using uniaxial compression tests on specimens, Park and
Bobet [15] observed that initiation stress of wing cracks increased with flaw inclination angle. Yang and Jing [16] conducted several groups of uniaxial compression tests to investigate the influence of the flaw angle on the strength and cracking behaviors of sandstone samples. Zhang and Wong [17] used a bonded particle model to simulate the influence of the flaw inclination angle on cracking process in rock-like materials containing a single flaw. They concluded that the flaw inclination angle had a strong influence on the crack initiation and propagation patterns. Manouchehrian et al. [18] used PFC2D (particle flow code in 2 dimensions) to study the influence of the flaw orientation on the crack propagation mechanism in brittle materials under various compressive loads and detected two types of secondary crack propagation mechanisms. Zhou et al. [19] conducted uniaxial compression tests for rock-like materials containing multiple flaws to further research the influences of the layout of preexisting flaws on mechanical properties and crack coalescence types. 
The closed flaw is one of the most common structural surfaces in rock mass, and the orientation of the flaw has an important influence on the cracking behavior of fractured rock. Although fruitful research findings were achieved in the past several decades, most of the experimental and numerical research studies were conducted on specimens containing open flaws. The influence of the inclination angle of closed flaw on the strength, cracking behavior, failure modes, and $\mathrm{AE}$ behaviors of specimens has not been investigated thoroughly. To address these problems, uniaxial compression tests were carried out on specimens containing a single flaw with four different flaw inclination angles. The experimental results are expected to provide helpful guidance for safe construction under fractured rock mass condition.

\section{Specimen Preparation and Testing System}

2.1. Specimen Preparation. In this experiment, the specimens were made from a mixture of water, high-strength gypsum, and quartz sand at a mass ratio of $1: 3: 0.5$. Rectangular prismatic specimens, with dimensions of $120 \times 60 \times 40 \mathrm{~mm}$ (height $\times$ width $\times$ thickness), shown in Figure 1, were prepared. The closed flaw in the specimen was made by inserting a sheet of resin flake, with thickness of $0.2 \mathrm{~mm}$ and length of $20 \mathrm{~mm}$, during the solidification period of the specimen. The resin flake was pulled out before the sample reached the final solidification strength, and the closed flaw naturally formed during the solidification process as a result of the characteristic of volume expansion of gypsum. To investigate the influences of the inclination angle of the preexisting flaw on the mechanical characteristics of the specimen under uniaxial compression, four different inclination angles were designed. The inclination angle $\alpha$ (the angle of the flaw to the horizontal direction) of the flaw is $30^{\circ}, 45^{\circ}, 60^{\circ}$, and $75^{\circ}$, as shown in Figure 1 . The physical and mechanical parameters of the specimen are listed in Table 1.

2.2. Testing System. The testing system as shown in Figure 2 includes loading equipment, AE monitoring equipment, and high-speed camera. The RMT-150C rock mechanics servo-controlled testing system, developed by the Institute of Rock and Soil Mechanics, Chinese Academy of Sciences, was chosen as the loading equipment. All tests were carried out under displacement control conditions with a loading rate of $0.002 \mathrm{~mm} / \mathrm{s}$. The $\mathrm{AE}$ signals were recorded by a DISP full-information AE measuring system made by American Physical Acoustics Corporation. In order to effectively remove the noise and to get the real AE signals generated by the specimens, the threshold value of $\mathrm{AE}$ signals was set to $40 \mathrm{db}$. The frequency of AE system was fixed to $1 \mathrm{MHz}$.

\section{Analysis of Experimental Results}

3.1. Characteristics of Strength and Deformation. Typical axial stress-strain curves for specimens containing single flaw under uniaxial compression are shown in Figure 3. As can be seen from Figure 3, the curve shape is obviously different for samples containing different flaw inclination angles which indicate that the flaw inclination angle has an important influence on the mechanical behavior of samples under uniaxial compression.

It can be seen from Figure 3 that after the peak strength, the load value drops rapidly and gradually stabilizes to a certain constant value, which is the residual strength of the sample. The residual strength of the sample indicates that the bearing capacity is not decreasing and no new cracks are produced in the sample. In the residual strength phase, continued loading is meaningless for the purposes of this study. Therefore, after the macroscopic damage of the sample, that is, the stress-strain curve shows obvious characteristics of residual strength, the loading stops.

The influence of the flaw inclination angle is investigated on the strength and deformation parameters of specimens under uniaxial compression, which are listed in Table 2. Three samples were tested under each flaw inclination condition. It should be pointed out that the test data with large deviation are not listed in Table 2. The definition for the mechanical parameters in Table 2 is described as follows. $E$ denotes the elastic modulus, $\sigma_{\mathrm{i}}$ is the wing crack initiation stress, $\sigma_{\mathrm{p}}$ is the uniaxial compressive stress, and $\sigma_{\mathrm{r}}$ represents the residual stress.

Before analyzing the flaw orientation influence on strength and deformation parameters of specimens, it should be pointed out that a comprehensive method based on the stress-strain and AE hit curve of the specimen was used to determine the wing crack initiation strength $\sigma_{\mathrm{i}}$. Taking the sample 30-2, which contains a flaw with an inclination angle of $30^{\circ}$, as an example, the comprehensive method to determine $\sigma_{\mathrm{i}}$ is analyzed as follows. The curve of stress-strain and AE hit of 30-2 is shown in Figure 4. As can be seen from Figure 4, the AE hit rate stayed at a low level during the stage of fissure closure and elastic deformation. However, when the axial stress increased to about 26.49 $\mathrm{MPa}$, the wing crack emanated from the tip of flaw. The corresponding axial stress dropped rapidly from 26.49 $\mathrm{MPa}$ to $26.20 \mathrm{MPa}$; meanwhile, the $\mathrm{AE}$ hit rate increased abruptly to about 120 times per second. Therefore, the wing crack initiation strength $\sigma_{\mathrm{i}}$ of sample 30-2 is identified as $26.49 \mathrm{MPa}$.

The influence of the flaw inclination angle on $\sigma_{\mathrm{i}}, \sigma_{\mathrm{p}}, \sigma_{\mathrm{r}}$, and $E$ of specimens containing a single flaw is demonstrated in Figure 5. Combined with the experimental curves drawn in Figure 5 and experimental results listed in Table 2, the influence of the flaw inclination angle on $\sigma_{\mathrm{i}}, \sigma_{\mathrm{p}}, \sigma_{\mathrm{r}}$, and $E$ of specimens containing a single flaw is analyzed as follows.

The influence law of $\alpha$ on the elastic modulus of the specimen is shown in Figure 5(a). E first decreased and then increased and reached the minimum value at $45^{\circ}$. As $\alpha$ increased from $30^{\circ}$ to $45^{\circ}$, the average value of $E$ decreased from $13.30 \mathrm{Gpa}$ to $12.83 \mathrm{GPa}$. However, the average value of $E$ showed a steady increasing trend from $12.83 \mathrm{GPa}$ to 13.53 GPa with the increase of $\alpha$ from $45^{\circ}$ to $75^{\circ}$.

Figure 5(b) shows the influence of $\alpha$ on the uniaxial compression strength of specimens, which is similar to the variation tendency on the elastic modulus. The average value 


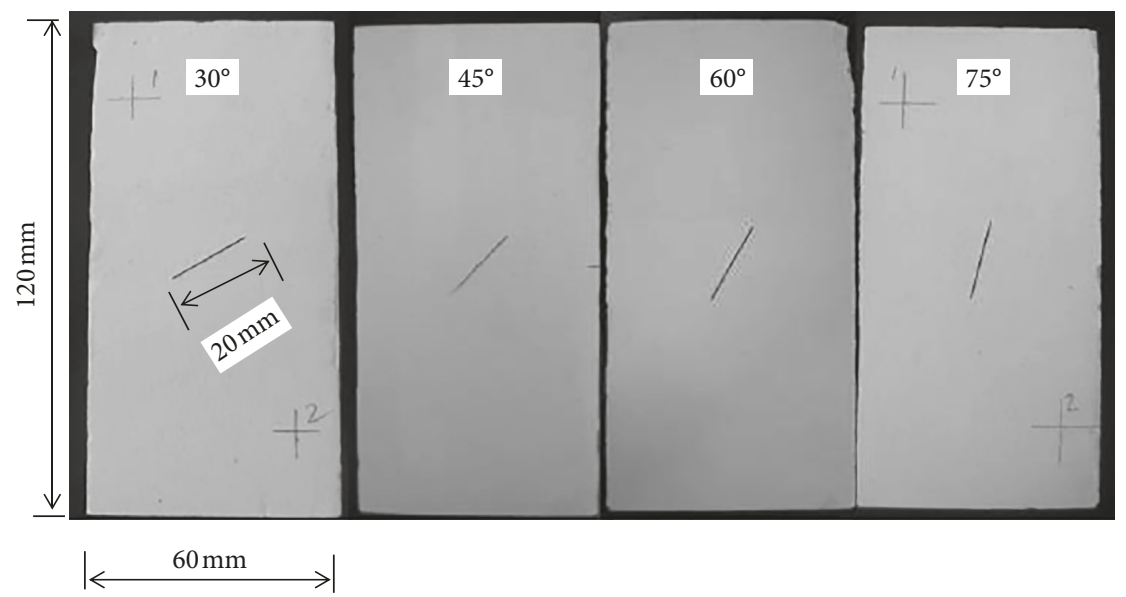

Figure 1: Geometry of the specimens.

Table 1: Physical and mechanical parameters of the specimen.

\begin{tabular}{lcccc}
\hline Uniaxial compressive strength $(\mathrm{MPa})$ & Elastic modulus $(\mathrm{GPa})$ & Tensile strength $(\mathrm{MPa})$ & Dry density $\left(\mathrm{g} \cdot \mathrm{cm}^{-3}\right)$ & Poisson's ratio \\
\hline 39.27 & 13.46 & 1.48 & 1.83 & 0.23 \\
\hline
\end{tabular}

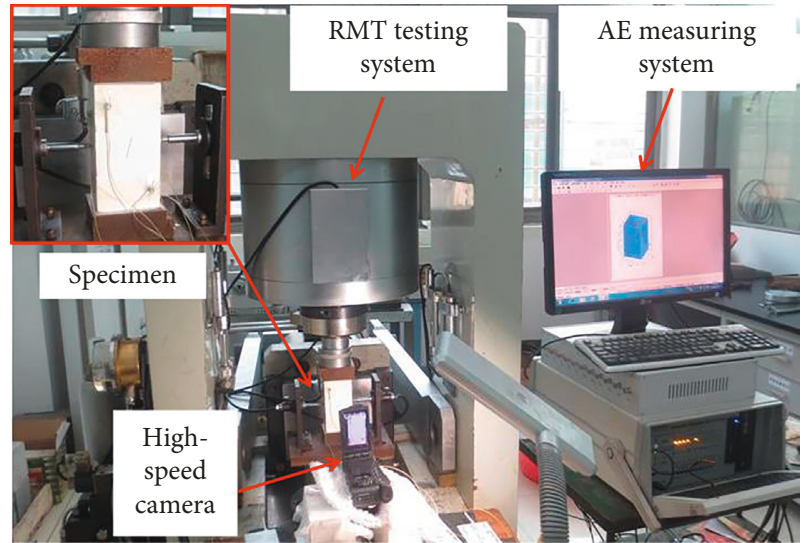

FIGURE 2: Test loading, acoustic emission monitoring, and camera system.

of $\sigma_{\mathrm{p}}$ at $\alpha=30^{\circ}$ is $33.54 \mathrm{MPa}$, but the average value of $\sigma_{\mathrm{p}}$ at $\alpha=45^{\circ}$ decreases to $28.80 \mathrm{MPa}$. With the increase of $\alpha$ from $45^{\circ}$ to $75^{\circ}$, the average $\sigma_{\mathrm{p}}$ shows a steady increasing trend from $28.80 \mathrm{Mpa}$ to $32.85 \mathrm{MPa}$.

Figures 5(c)-5(e) reveal the influence of the flaw inclination angle on the wing crack initiation strength $\sigma_{\mathrm{i}}$ and the ratio of $\sigma_{\mathrm{i}}$ to $\sigma_{\mathrm{p}}$, respectively. After comparing the two curves plotted in Figures 5(c)-5(e), it is very clear that both $\sigma_{\mathrm{i}}$ and $\sigma_{\mathrm{i}} / \sigma_{\mathrm{p}}$ have a similar trend with the increase of the flaw inclination angle from $30^{\circ}$ to $75^{\circ}$. The two parameters decreased in the range from $30^{\circ}$ to $45^{\circ}$ and then increased from $45^{\circ}$ to $75^{\circ}$. For instance, when $\alpha$ increased from $30^{\circ}$ to $45^{\circ}$, the average wing crack initiation strength decreased from 25.69 $\mathrm{MPa}$ to $17.49 \mathrm{MPa}$. However, when $\alpha$ increased from $45^{\circ}$ to $75^{\circ}$, the average wing crack initiation strength increased from 17.49 $\mathrm{MPa}$ to $31.85 \mathrm{MPa}$.

It needs to be mentioned that the ratio of $\sigma_{\mathrm{i}} / \sigma_{\mathrm{p}}$ can be used to describe the degree of difficulty of the initiation of

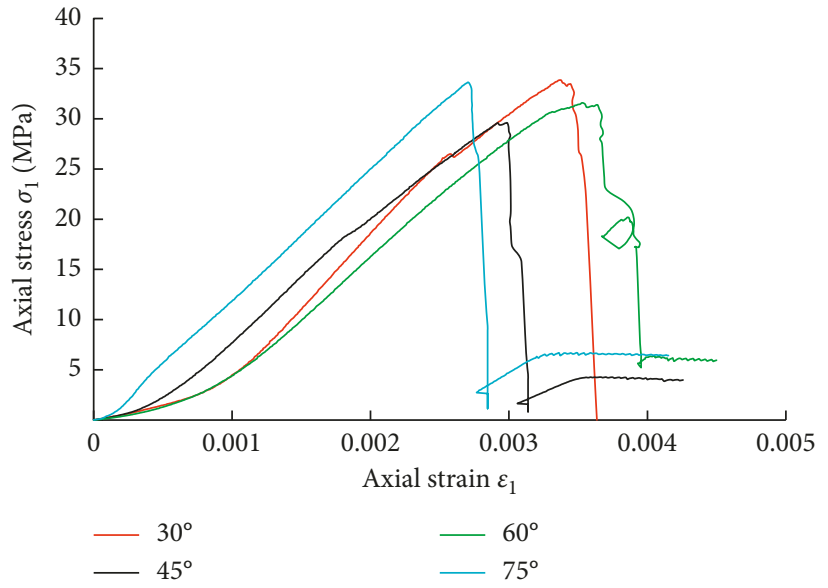

FIgURE 3: Axial stress-strain curves of specimens containing a single flaw under uniaxial compression.

TABLE 2: Mechanical parameters of specimens containing a single flaw under uniaxial compression.

\begin{tabular}{ccccccc}
\hline$\alpha\left(^{\circ}\right)$ & Sample & $E(\mathrm{GPa})$ & $\sigma_{\mathrm{i}}(\mathrm{MPa})$ & $\sigma_{\mathrm{p}}(\mathrm{MPa})$ & $\sigma_{\mathrm{i}} / \sigma_{\mathrm{p}}(\%)$ & $\sigma_{\mathrm{r}}(\mathrm{MPa})$ \\
\hline \multirow{2}{*}{30} & $30-1$ & 13.49 & 24.88 & 33.21 & 74.92 & 0 \\
& $30-2$ & 13.11 & 26.49 & 33.86 & 78.23 & 3.64 \\
\hline \multirow{2}{*}{45} & $45-1$ & 12.42 & 17.38 & 28.01 & 62.07 & 4.71 \\
& $45-2$ & 13.24 & 17.60 & 29.59 & 59.48 & 3.98 \\
\hline \multirow{2}{*}{60} & $60-1$ & 12.73 & 29.41 & 31.58 & 93.13 & 5.98 \\
& $60-2$ & 13.39 & 28.44 & 30.98 & 91.80 & 7.89 \\
\hline \multirow{2}{*}{75} & $75-1$ & 14.07 & 31.64 & 32.08 & 98.63 & 7.51 \\
& $75-2$ & 12.99 & 32.06 & 33.62 & 95.36 & 6.87 \\
\hline
\end{tabular}

wing crack. According to the experimental results concluded by Zhao et al. [20], the ratio of $\sigma_{\mathrm{i}} / \sigma_{\mathrm{p}}$ of gypsum samples containing open flaws with different inclination angles is plotted in Figure 6. From Figure 6, we can conclude that the 


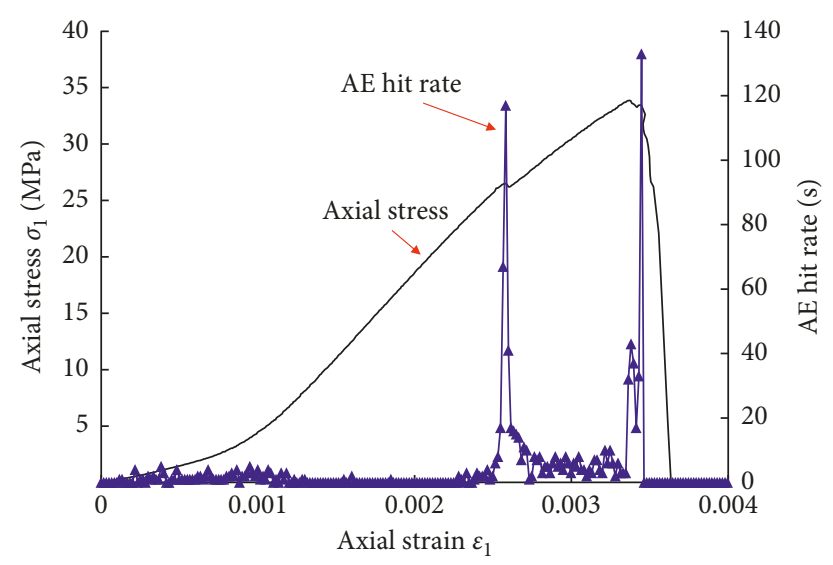

FIgURE 4: Stress-strain and AE hit curve of the specimen 30-2.

wing crack is more difficult to initiate from the tips of closed flaws compared with that of open flaws.

Figure 5(d) is a plot of the residual strength $\sigma_{\mathrm{r}}$ versus the flaw inclination angle $\alpha$. The change rule is that $\sigma_{\mathrm{r}}$ kept increasing with the flaw inclination angle $\alpha$. The minimum average value of $\sigma_{\mathrm{r}}\left(\alpha=30^{\circ}\right)$ was $1.82 \mathrm{MPa}$, and the maximum average value of $\sigma_{\mathrm{r}}$ was $7.19 \mathrm{MPa}\left(\alpha=75^{\circ}\right)$.

3.2. Cracking Behaviors. When a crack is stably expanded, the slowly expanding path can be clearly observed from the captured video. Moreover, the stable expansion of the crack can be promoted only when the axial load continues to increase. In the form of the stress-strain curve, the crack is stably expanded and the load is slowly increased. At the same time, the acoustic emission hit rate and energy of the sample will also show a slowly increasing trend. When the crack is unstably expanding, its expansion speed is very fast, and it is difficult to capture its expansion path from the captured video. At the same time, even if the axial load does not continue to increase, the crack will spontaneously expand. At the same time, the acoustic emission hit rate and energy of the sample will show a sharply increasing trend.

Taking the sample 30-2, which contains a flaw with an inclination angle of $30^{\circ}$, as an example, the cracking characteristics and failure process are described as follows. Tensile wing crack initiated when axial stress reached 26.49 $\mathrm{MPa}$ (see Figure 7(a), T stands for tensile wing crack). The generation of the wing crack resulted in a small drop of axial stress. With the further increase of axial stress, the wing crack lengthened and propagated to the edge of the sample (as can be seen from Figure 7(a)). When the sample was loaded to about $32.5 \mathrm{MPa}$, the secondary crack emanated from the upper tip of flaw. The secondary crack was originally shear crack and propagated in the plane of the flaw in a stable manner (see Figure $7(\mathrm{~b}), \mathrm{S}$ stands for shear crack). The propagation of the secondary crack resulted in surface spalling phenomenon around the area of propagation route (see Figure $7(\mathrm{c}$ ), the grey area represents surface spalling). When the axial stress reached the peak strength, the secondary crack propagated in an unstable manner toward the upper boundary of the sample which resulted in an obvious shear movement along the plane of flaw.

As can be seen from Figures 8(a)-8(c), for the specimens containing a single flaw with the inclination angle of $45^{\circ}$, its cracking process is very similar to that of specimens containing a single flaw with the inclination angle of $30^{\circ}$. In fact, for the specimens containing a single flaw with the inclination angle of $60^{\circ}$ and $75^{\circ}$, their cracking processes are all similar to those of specimens containing a single flaw with the inclination angle of $30^{\circ}$. However, for the specimens containing a single flaw with the inclination angle of $0^{\circ}$ and $90^{\circ}$, no cracks were observed to initiate from the tips of the flaw during the whole loading process which is consistent with the numerical simulation results conducted by Liu and Yang [21]. This phenomenon is very different from that conducted on samples containing open flaws $[6,7,17,18,22]$. The reason for this phenomenon may be due to the large coefficient of friction between the preexisting flaw surfaces.

Furthermore, the influence of the flaw inclination angle $\alpha$ on the wing crack initiation angle $\theta$ (the angle between the tangential direction of the wing crack and the long axis of the preexisting flaw as shown in Figure 7(a)) is also analyzed as demonstrated in Figure 9. The results show that wing crack initiation angle $\theta$ decreased from $65^{\circ}$ to $35^{\circ}$ as the flaw inclination angle $\alpha$ increased from $30^{\circ}$ to $75^{\circ}$. The change trend is consistent with that conducted on samples containing open flaws [14].

There is one point that should be pointed out. Yang and Jing [16] categorized nine different crack types based on their geometry and crack propagation mechanism of sandstone samples containing a single flaw under uniaxial compression. However, in this experimental investigation, there are only two main types of cracks, e.g., the tensile wing crack and the shear secondary crack initiated from the tips of the flaw. Three main reasons can be concluded to explain this discrepancy. The fist and the most important point is the difference in the type of the flaw. In this research, we adopted a closed flaw, but in Yang's research, he used an open one. The second one is the difference of experimental material. The sample used by Yang is sandstone, but high-strength gypsum is used in this experiment. The third point is the 


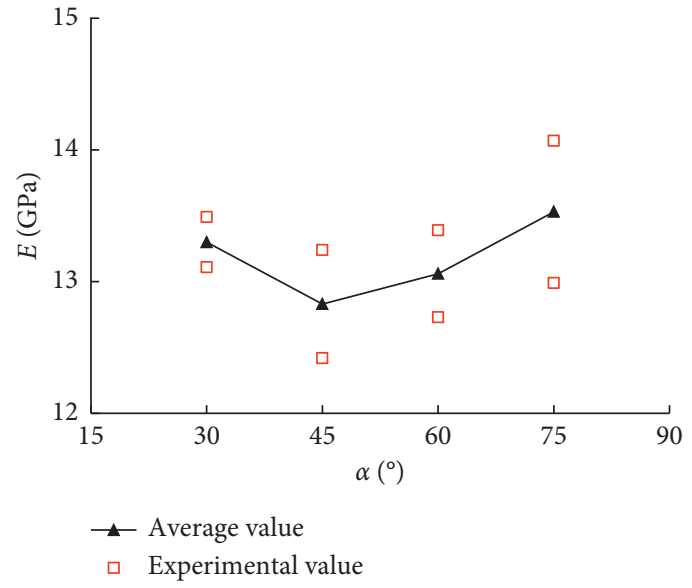

(a)

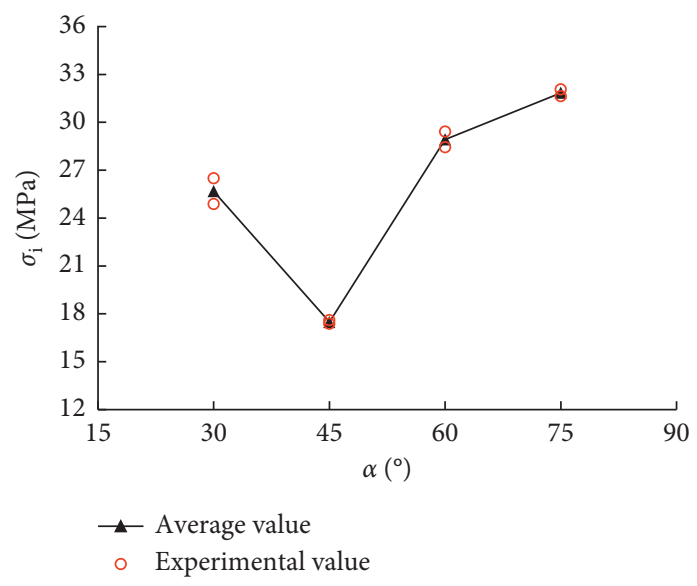

(c)

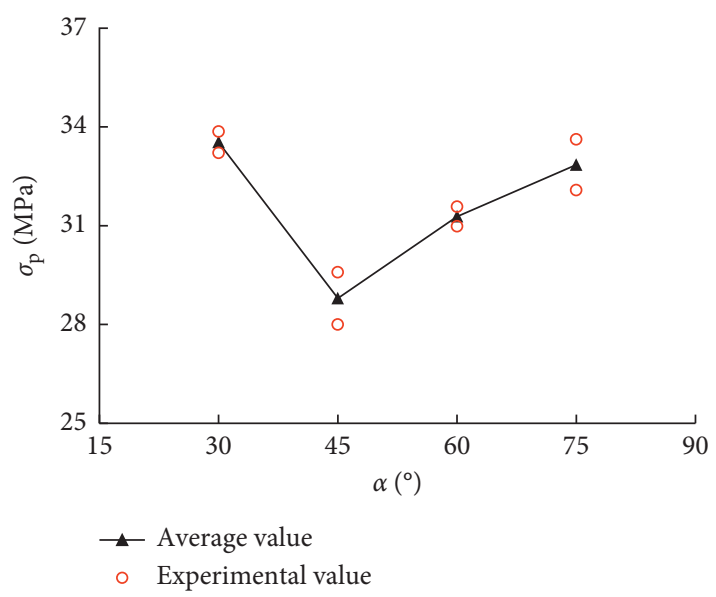

(b)

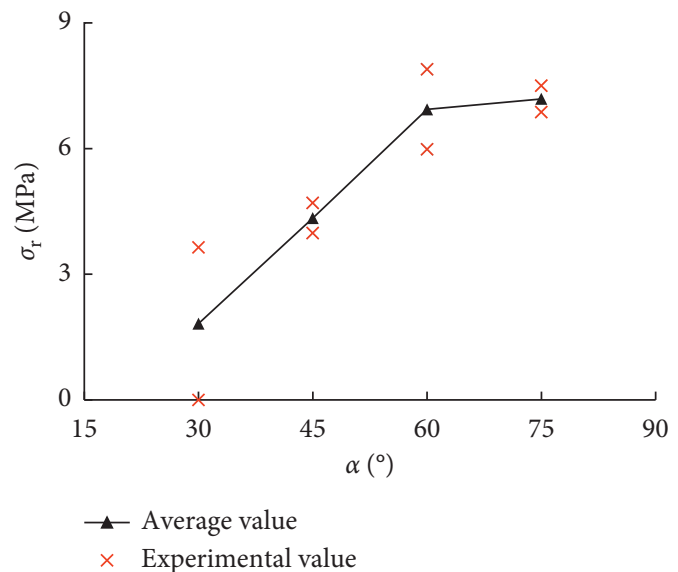

(d)

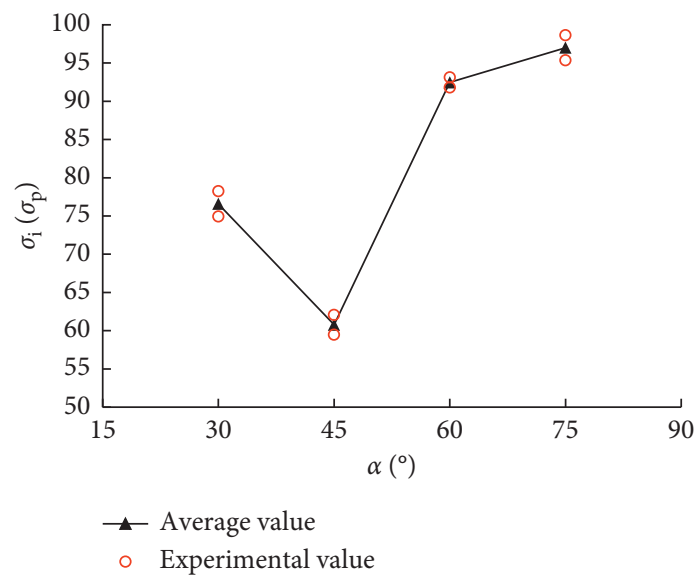

(e)

FIGURE 5: Influence of the flaw inclination angle on the strength and deformation parameters of specimens under uniaxial compression: (a) elastic modulus; (b) uniaxial compressive strength; (c) wing crack initiation strength; (d) residual strength; (e) ratio of $\sigma_{\mathrm{i}} / \sigma_{\mathrm{p}}$.

difference in the length of the flaws. Further research will be conducted to reveal the inherent reasons.

3.3. Failure Modes. Typical failure modes of specimens containing a single flaw with different inclinations are described in Figure 10. For specimens containing a single flaw with the inclination angle of $30^{\circ}$ (Figure $10(\mathrm{a})$ ), $45^{\circ}$ (Figure $\left.10(\mathrm{~b})\right), 60^{\circ}$ (Figure $10(\mathrm{c})$ ), and $75^{\circ}$ (Figure $10(\mathrm{~d})$ ), they exhibit similar failure modes. The initiation and propagation of wing crack destroyed the integrity of the sample. However, the initiation and propagation of secondary crack resulted in the ultimate macrofracture of samples. After the experiment, as shown in Figure 11, the 


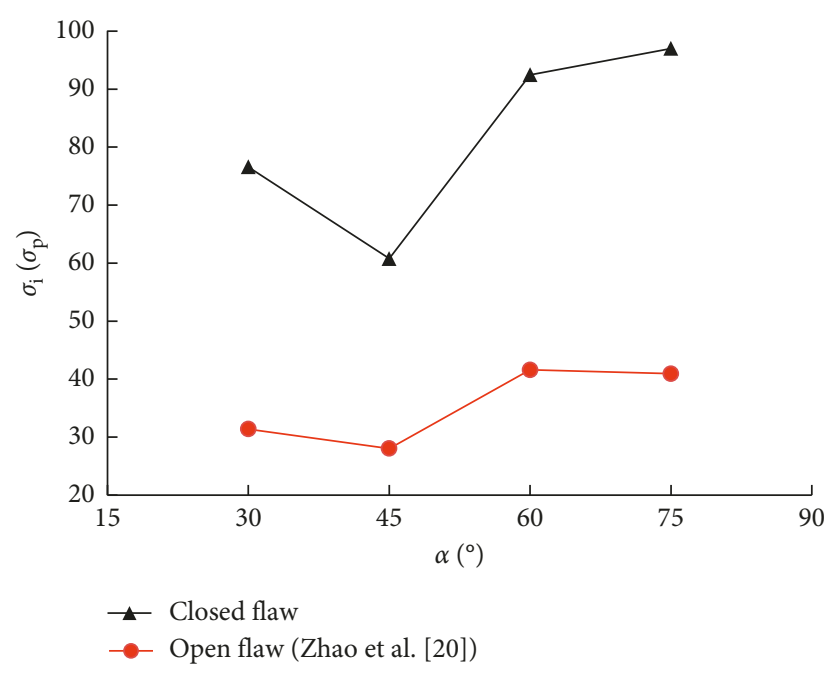

FIgURE 6: Influence of the flaw inclination angle on the ratio of $\sigma_{\mathrm{i}} / \sigma_{\mathrm{p}}$.

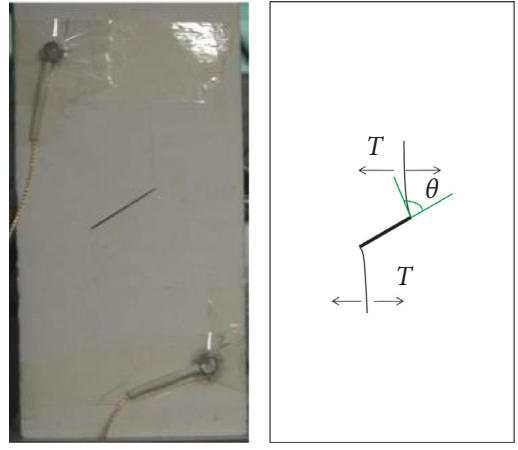

(a)

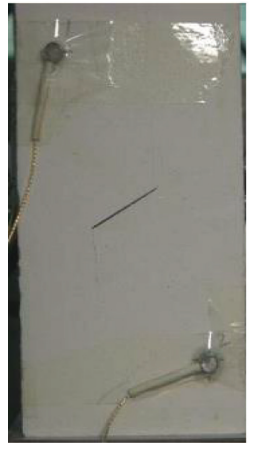

(b)

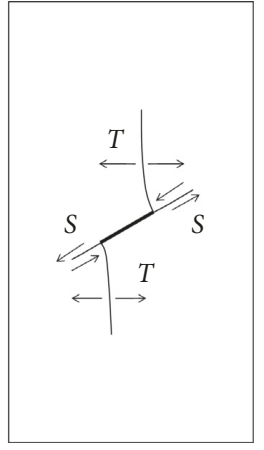

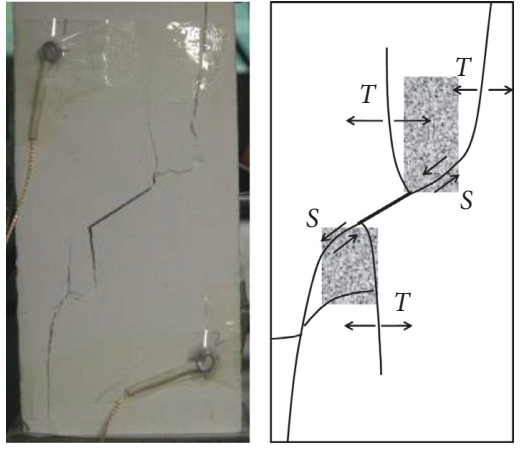

(c)

FiguRE 7: Crack initiation and propagation process of sample 30-2 under uniaxial compression: (a) wing crack initiation and propagation; (b) secondary crack initiation and propagation; (c) ultimate failure.

fractured sample can be easily forced apart with hands along the irregular plane of propagation tracks of secondary crack.

\section{Acoustic Emission Characteristics}

As a nondestructive testing method, the acoustic emission (AE) monitoring technique has been widely used to better understand the failure process of rock in laboratory $[23,24]$. Figure 12 shows the $\mathrm{AE}$ hit rate and AE cumulative energy of some typical samples in the process of uniaxial compression test. From Figure 12, one can find that for all the samples containing a single flaw with different inclinations, both the $\mathrm{AE}$ hit rate and $\mathrm{AE} \mathrm{cu}-$ mulative energy remained at a very low level in the stage of fissure closure and elastic deformation.

For the samples containing a single flaw with the inclination angle of $30^{\circ}$ (Figure $12(\mathrm{a})$ ), $45^{\circ}$ (Figure 12(b)), $60^{\circ}$ (Figure $12(\mathrm{c})$ ), and $75^{\circ}$ (Figure $12(\mathrm{~d})$ ), the AE hit rate increased sharply due to the initiation of wing crack. Meanwhile, the AE cumulative energy increased abruptly to a high level. As the axial stress reached the peak strength, both the $\mathrm{AE}$ hit rate and cumulative energy increased abruptly due to the unstable propagation of secondary crack which resulted in the ultimate failure of the sample.

The AE events were very few at the stage of residual strength for the samples containing a single flaw with the inclination of $30^{\circ}, 45^{\circ}$ and $75^{\circ}$. However, for the samples containing a single flaw with the inclination of $60^{\circ}$, as shown in Figure 12(c), the AE events still maintained a certain level of activity which is characterized by several slight increases of the AE cumulative energy. The reason for this phenomenon is that some certain parts of the samples broke off due to the constraint influence of the loading plate.

\section{Conclusions}

Uniaxial compressive tests were carried out to investigate the strength, cracking process, failure modes, and AE behaviors of rock-like materials containing a single closed flaw with four different inclination angles from $30^{\circ}$ to $75^{\circ}$. The following conclusions can be summarized based on the analysis of experimental results. 

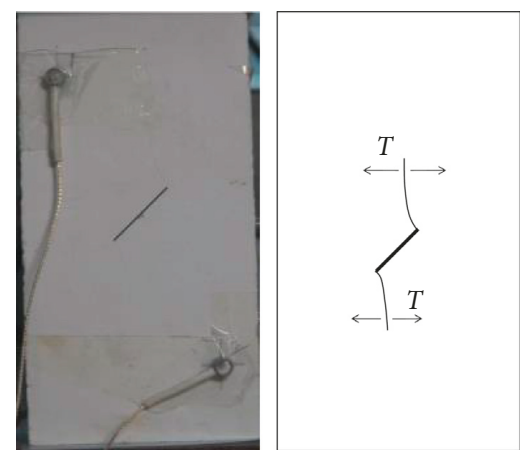

(a)

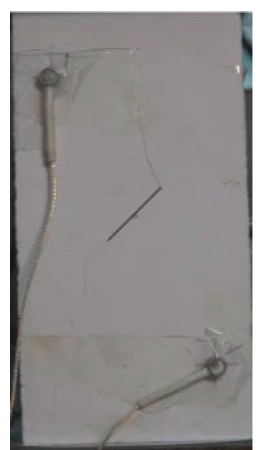

(b)
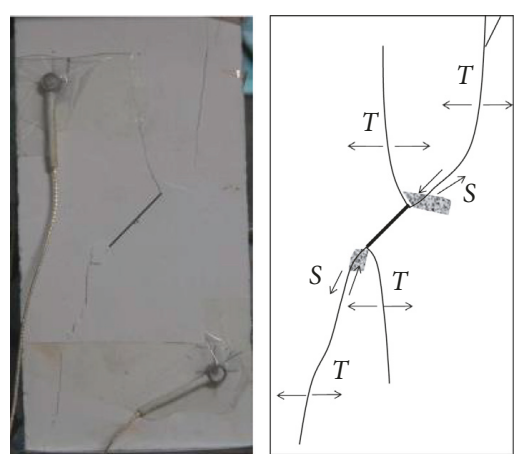

(c)

FIGURE 8: Crack propagation process of sample 45-1 under uniaxial compression: (a) wing crack initiation and propagation; (b) secondary crack initiation and propagation; (c) ultimate failure.

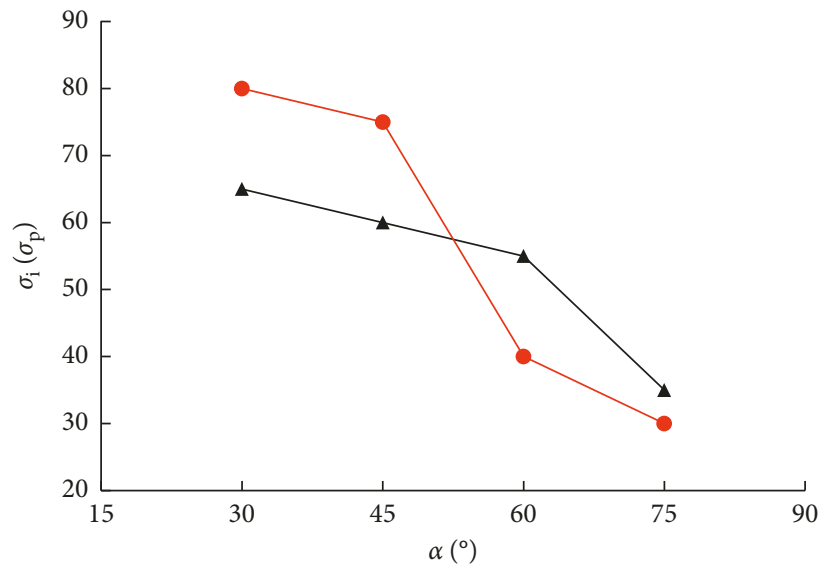

$\leftarrow$ Closed flaw

Open flaw (Bobet and Einstein [14])

FIgURe 9: Influence of the flaw inclination angle on the wing crack initiation angle.

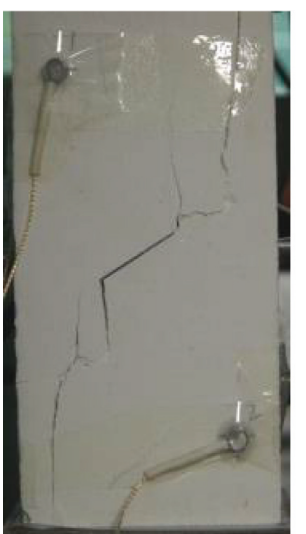

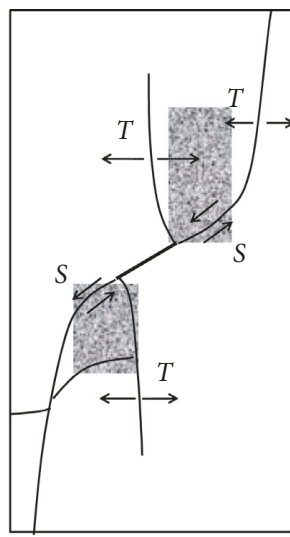

(a)
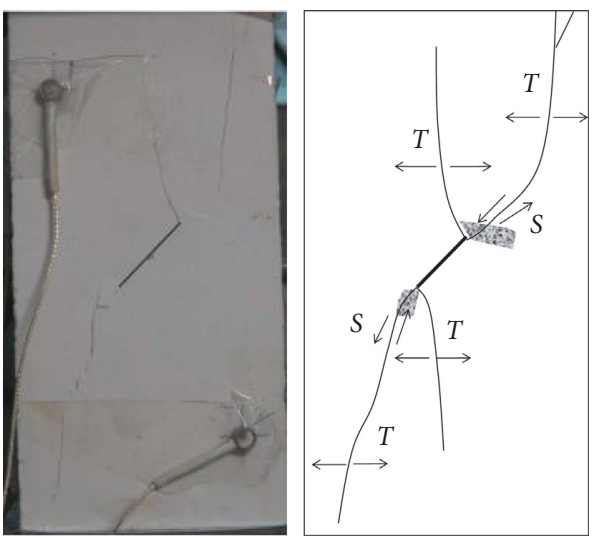

(b)

Figure 10: Continued. 

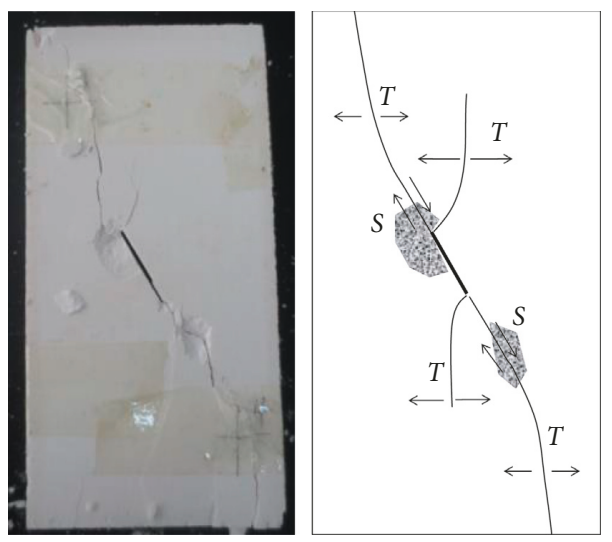

(c)
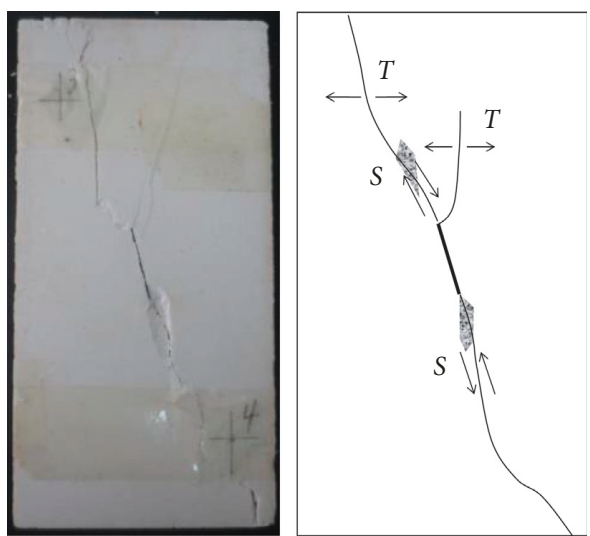

(d)

FIGURE 10: Failure modes of specimens containing a single flaw with different inclination angles under uniaxial compression: (a) $\alpha=30^{\circ}$; (b) $\alpha=45^{\circ}$; (c) $\alpha=60^{\circ}$; (d) $\alpha=75^{\circ}$.
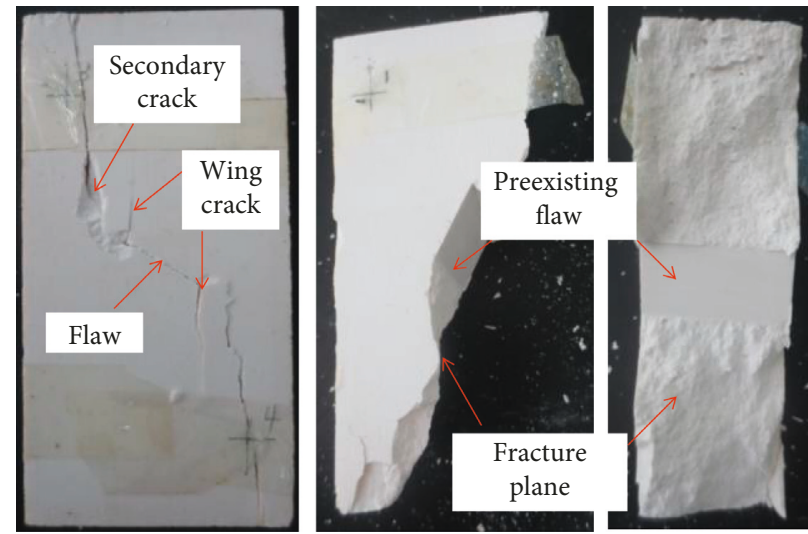

FIGURE 11: Internal rupture of sample.

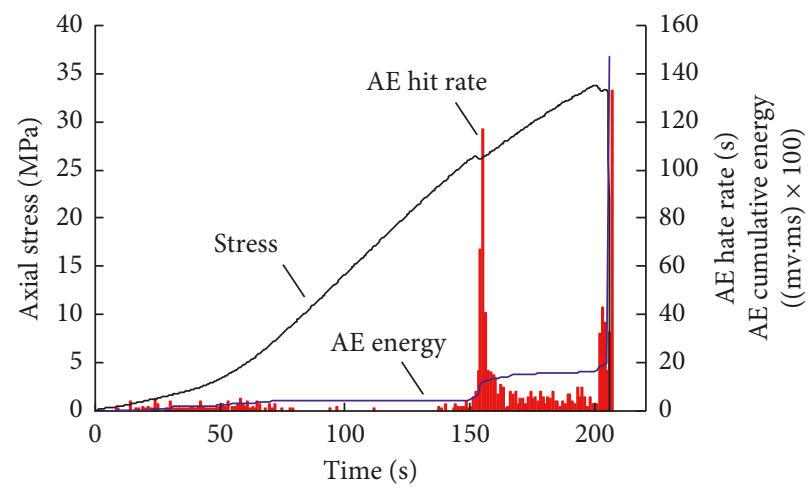

(a)

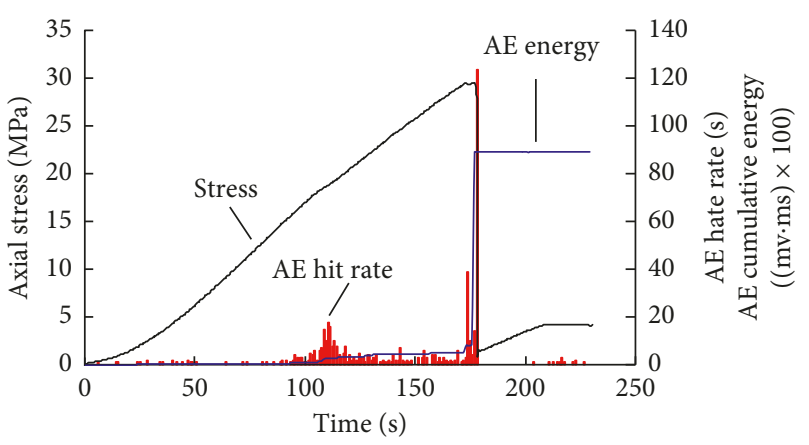

(b)

Figure 12: Continued. 


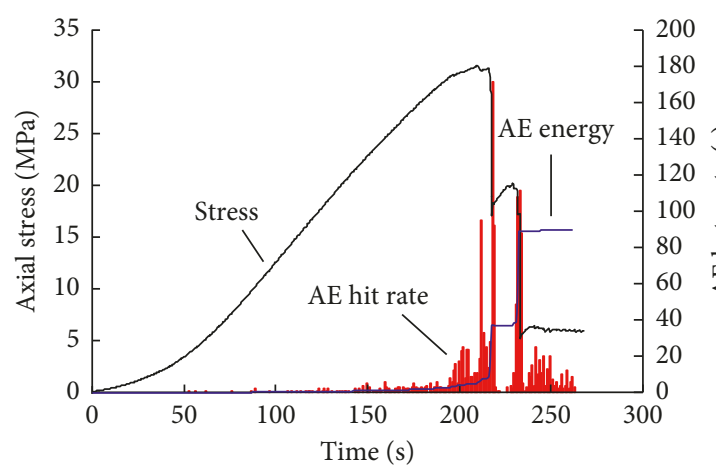

(c)

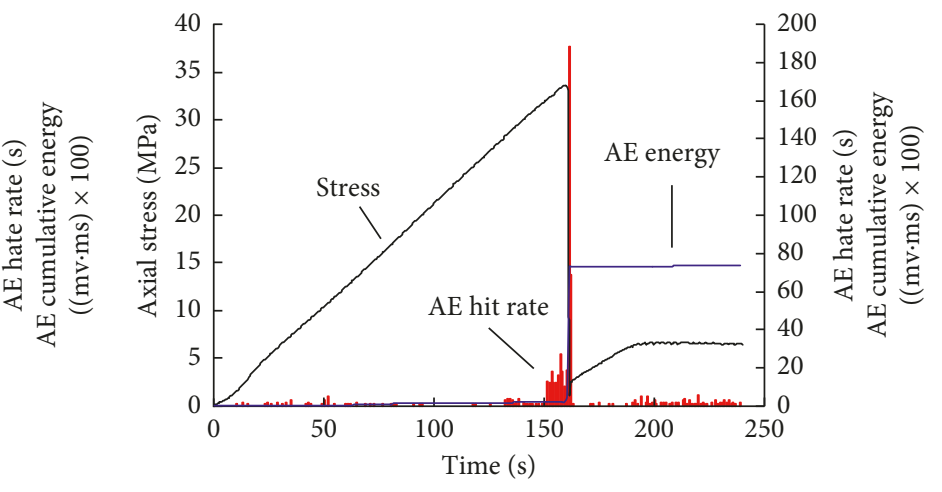

(d)

Figure 12: Relation between axial stress, AE hit rate, AE cumulative energy, and time of samples containing a single flaw with different inclinations: (a) $\alpha=30^{\circ}$; (b) $\alpha=45^{\circ}$; (c) $\alpha=60^{\circ}$; (d) $\alpha=75^{\circ}$.

With the increase of the flaw inclination angle from $30^{\circ}$ to $75^{\circ}$, the corresponding mechanical parameters, such as elastic modulus $E$, wing crack initiation strength $\sigma_{\mathrm{i}}$, and uniaxial compressive strength $\sigma_{\mathrm{p}}$, decrease first and then increase and reach the minimum value at $45^{\circ}$. However, the residual strength $\sigma_{\mathrm{r}}$ exhibits an increasing tendency with flaw inclination angle. The wing crack is more difficult to initiate from the tips of closed flaws compared with that of open flaws.

Wing crack and secondary crack were detected in the specimens containing flaws with the inclination angle of $30^{\circ}$, $45^{\circ}, 60^{\circ}$, and $75^{\circ}$. Wing crack initiation angle $\theta$ decreases from $65^{\circ}$ to $35^{\circ}$ as the flaw inclination angle $\alpha$ increases from $30^{\circ}$ to $75^{\circ}$. The secondary cracks are originally shear cracks and propagate in a stable manner in a plane coplanar with the flaw. However, when the axial stress reaches the peak strength, the secondary crack propagates in an unstable manner which results in the ultimate failure of the specimens.

For the samples containing a single flaw with the inclination angle of $30^{\circ}, 45^{\circ}, 60^{\circ}$, and $75^{\circ}$, the AE hit rate increases sharply due to the initiation of wing crack. When the axial stress reaches the peak strength, both the $\mathrm{AE}$ hit rate and cumulative energy increase abruptly due to the unstable propagation of secondary crack which results in the ultimate failure of the sample.

\section{Data Availability}

Any reader or researcher who wishes to obtain the research data of this article can contact the author by e-mail.

\section{Conflicts of Interest}

The author declares no conflicts of interest.

\section{Acknowledgments}

The author would like to acknowledge the financial support provided by the National Natural Science Foundation of China under grant no. 51709113.

\section{References}

[1] C. A. Tang and S. Q. Kou, "Crack propagation and coalescence in brittle materials under compression," Engineering Fracture Mechanics, vol. 61, no. 3-4, pp. 311-324, 1998.

[2] R. H. C. Wong, K. T. Chau, C. A. Tang, and P. Lin, "Analysis of crack coalescence in rock-like materials containing three flaws-Part I: experimental approach," International Journal of Rock Mechanics and Mining Sciences, vol. 38, no. 7, pp. 909-924, 2001.

[3] Y.-P. Li, L.-Z. Chen, and Y.-H. Wang, "Experimental research on pre-cracked marble under compression," International Journal of Solids and Structures, vol. 42, no. 9-10, pp. 25052516, 2005.

[4] L. N. Y. Wong and H. H. Einstein, "Crack coalescence in molded gypsum and carrara marble: part 1. Macroscopic observations and interpretation," Rock Mechanics and Rock Engineering, vol. 42, no. 3, pp. 475-511, 2009.

[5] L. N. Y. Wong and H. H. Einstein, "Systematic evaluation of cracking behavior in specimens containing single flaws under uniaxial compression," International Journal of Rock Mechanics and Mining Sciences, vol. 46, no. 2, pp. 239-249, 2009.

[6] H. Lee and S. Jeon, "An experimental and numerical study of fracture coalescence in pre-cracked specimens under uniaxial compression," International Journal of Solids and Structures, vol. 48, no. 6, pp. 979-999, 2011.

[7] S.-Q. Yang, X.-R. Liu, and H.-W. Jing, "Experimental investigation on fracture coalescence behavior of red sandstone containing two unparallel fissures under uniaxial compression," International Journal of Rock Mechanics and Mining Sciences, vol. 63, no. 5, pp. 82-92, 2013.

[8] S.-Q. Yang, Y.-H. Huang, H.-W. Jing, and X.-R. Liu, "Discrete element modeling on fracture coalescence behavior of red sandstone containing two unparallel fissures under uniaxial compression," Engineering Geology, vol. 178, no. 6, pp. 28-48, 2014.

[9] S.-Q. Yang, W.-L. Tian, Y.-H. Huang, P. G. Ranjith, and Y. Ju, "An experimental and numerical study on cracking behavior of brittle sandstone containing two non-coplanar fissures under uniaxial compression," Rock Mechanics and Rock Engineering, vol. 49, no. 4, pp. 1497-1515, 2016.

[10] H. Haeri, K. Shahriar, M. F. Marji, and P. Moarefvand, "Experimental and numerical study of crack propagation and coalescence in pre-cracked rock-like disks," International 
Journal of Rock Mechanics and Mining Sciences, vol. 67, no. 4, pp. 20-28, 2014.

[11] H. Haeri, K. Shahriar, M. F. Marji, and P. Moarefvand, "A coupled numerical-experimental study of the breakage process of brittle substances," Arabian Journal of Geosciences, vol. 8, no. 2, pp. 809-825, 2015.

[12] V. Sarfarazi, A. Ghazvinian, W. Schubert, M. Blumel, and H. R. Nejati, "Numerical simulation of the process of fracture of echelon rock joints," Rock Mechanics and Rock Engineering, vol. 47, no. 4, pp. 1355-1371, 2014.

[13] X. P. Zhang, L. N. Y. Wong, and S. J. Wang, "Effects of the ratio of flaw size to specimen size on cracking behavior," Bulletin of Engineering Geology and the Environment, vol. 74, no. 1, pp. 181-193, 2016.

[14] A. Bobet and H. H. Einstein, "Fracture coalescence in rocktype materials under uniaxial and biaxial compression," International Journal of Rock Mechanics and Mining Sciences, vol. 35, no. 7, pp. 863-888, 1998.

[15] C. H. Park and A. Bobet, "Crack coalescence in specimens with open and closed flaws: a comparison," International Journal of Rock Mechanics and Mining Sciences, vol. 46, no. 5, pp. 819-829, 2009.

[16] S.-Q. Yang and H.-W. Jing, "Strength failure and crack coalescence behavior of brittle sandstone samples containing a single fissure under uniaxial compression," International Journal of Fracture, vol. 168, no. 2, pp. 227-250, 2011.

[17] X. P. Zhang and L. N. Y. Wong, "Cracking process in rock-like material containing a single flaw under uniaxial compression: a numerical study based on parallel bonded-particle model approach," Rock Mechanics and Rock Engineering, vol. 45, no. 5, pp. 711-737, 2012.

[18] A. Manouchehrian, M. Sharifzadeh, M. F. Marji, and J. Gholamnejad, "A bonded particle model for analysis of the flaw orientation effect on crack propagation mechanism in brittle materials under compression," Archives of Civil and Mechanical Engineering, vol. 14, no. 1, pp. 40-52, 2014.

[19] X. P. Zhou, H. Cheng, and Y. F. Feng, "An experimental study of crack coalescence behaviour in rock-like materials containing multiple flaws under uniaxial compression," Rock Mechanics and Rock Engineering, vol. 47, no. 6, pp. 1961-1986, 2014.

[20] C. Zhao, F. M. Liu, J. S. Tian, H. Matsuda, and C. Morita, "Study on single crack propagation and damage evolution mechanism of rock-like materials under uniaxial compression," Chinese Journal of Rock Mechanics and Engineering, vol. 35, no. 2, pp. 3626-3632, 2016, in Chinese.

[21] H. W. Liu and C. Yang, "Micro-analysis of uniaxial compression of cracked rock containing open or closing fissure based on PFC," Water Resources and Power, vol. 34, no. 1, pp. 131-135, 2016, in Chinese.

[22] C. Q. Ma, H. Z. Li, and Y. Niu, "Experimental study on damage failure mechanical characteristics and crack evolution of water-bearing surrounding rock," Environmental Earth Sciences, vol. 77, no. 1, p. 23, 2018.

[23] F. Meng, L. N. Y. Wong, H. Zhou, J. Yu, and G. Cheng, "Shear rate effects on the post-peak shear behaviour and acoustic emission characteristics of artificially split granite joints," Rock Mechanics and Rock Engineering, vol. 52, no. 7, pp. 2155-2174, 2019.

[24] R. Xu and H. Zhou, "Experimental investigation of the anchoring effect of two different types of rock bolts on fractured rock," Advances in Materials Science and Engineering, vol. 2019, Article ID 9290318, 10 pages, 2019. 


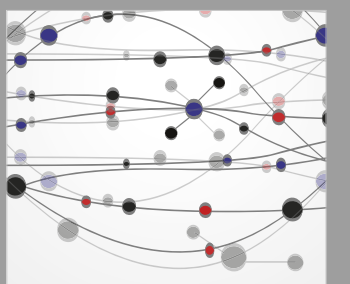

The Scientific World Journal
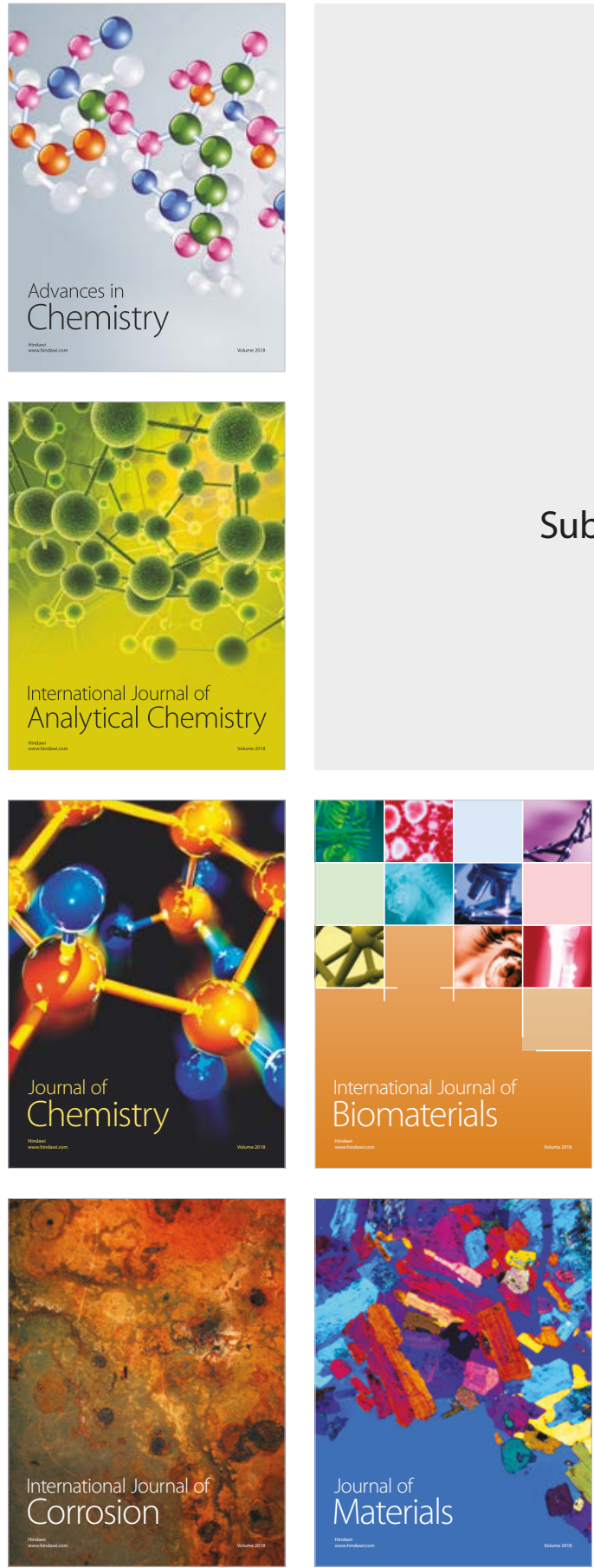

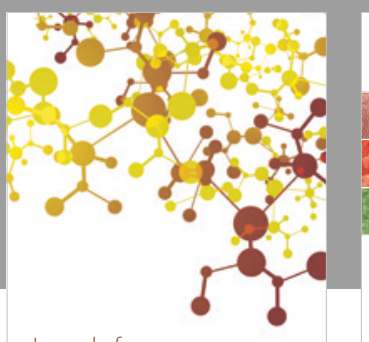

Journal of

Applied Chemistry
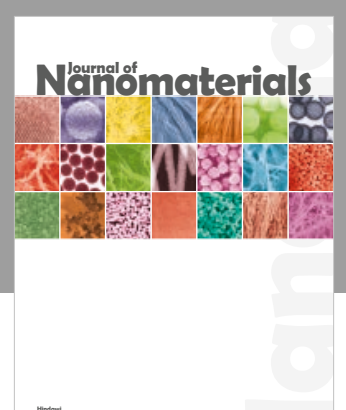

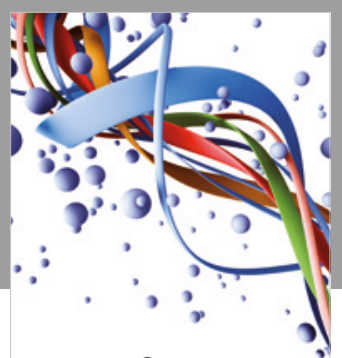

Scientifica

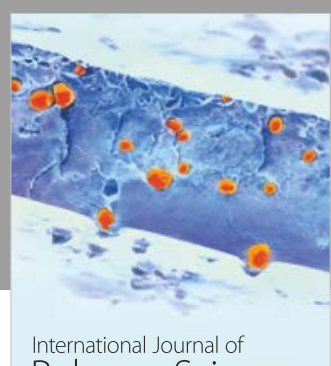

Polymer Science

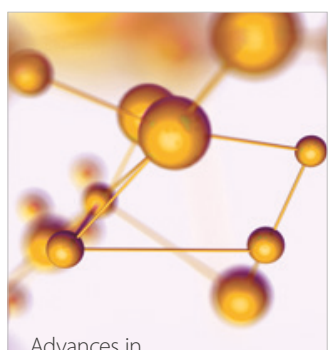

Physical Chemistry
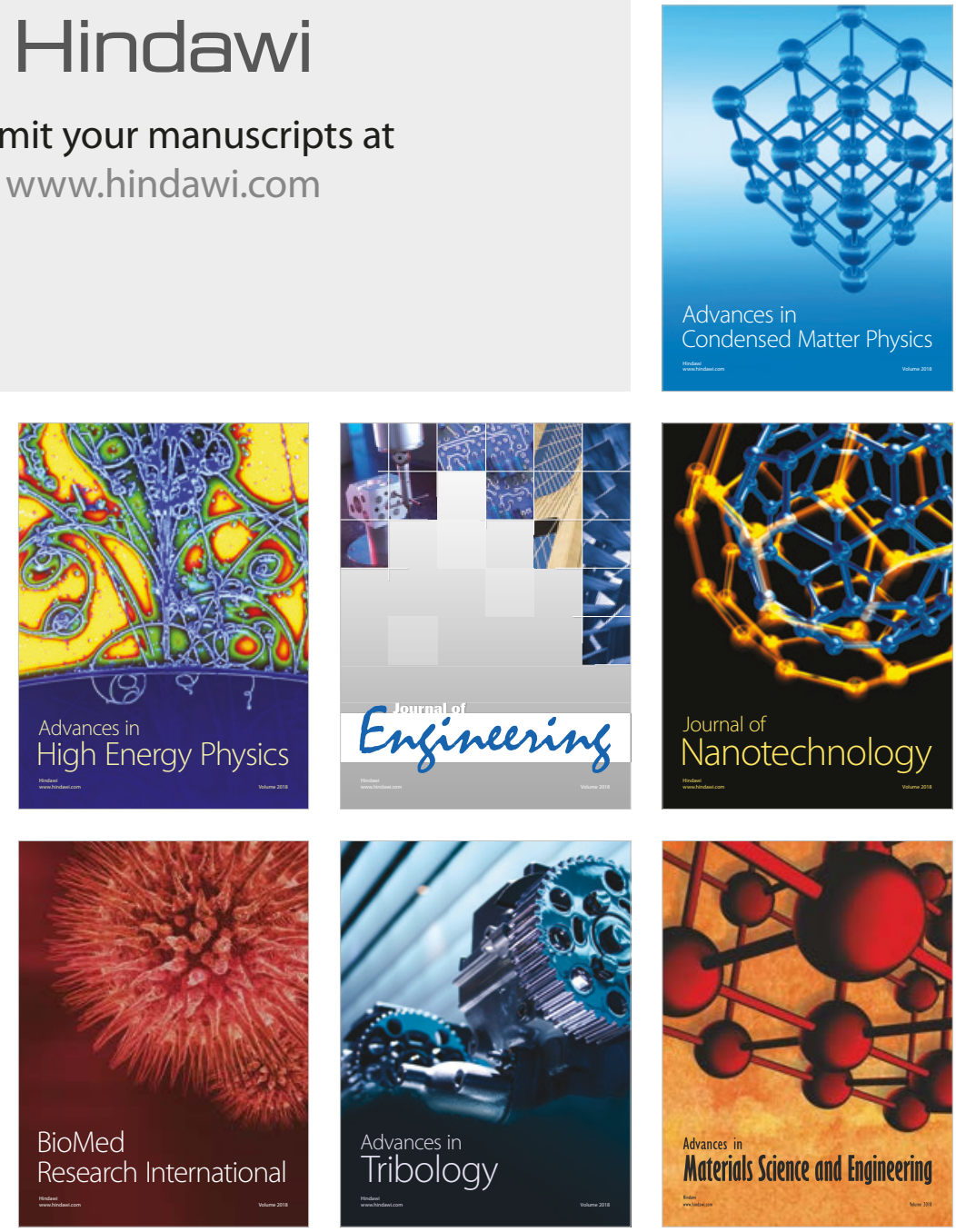